\title{
Properties of SBS and Sisal Fiber Composites: Ecological Material for Shoe Manufacturing
}

\author{
José Carlos Krause de Verney*, Martha Fogliato Santos Lima, Denise Maria Lenz \\ Programa de Pós-Graduação em Engenharia, Energia, Ambiente e Materiais, \\ Universidade Luterana do Brasil - ULBRA, \\ Av. Farroupilha, 8001, Prédio 29, sala 203, 92450-900 Canoas - RS, Brazil
}

Received: June 9, 2008; Revised: November 19, 2008

\begin{abstract}
The worldwide trend toward using cheap, atoxic and durable materials from renewable resources contributes to sustainable development. Thus, the investigation of the potential use of vegetal fibers as reinforcing agent in polymeric composites has gained new significance. Sisal fiber has emerged as a reinforcing material for polymers used in automobile, footwear and civil industries. In this work, properties such as hardness, tensile strength and tear strength of polymer composites composed by block copolymer styrene-butadiene-styrene (SBS) and 5, 10 and 20\% by weight of sisal fiber were evaluated. The influence of conventional polymer processing techniques such as single-screw and double-screw extrusion, as well as the addition of coupling agent on the composite mechanical performance was investigated. Also, the morphology and thermal stability of the composites were analyzed. The addition of 2 wt. (\%) maleic anhydride as coupling agent between sisal fiber and SBS has improved the composite mechanical performance and the processing in a double-screw extruder has favored the sisal fiber distribution in the SBS matrix.
\end{abstract}

Keywords: vegetal fibers, sisal, polymer composites, reinforcing agent, mechanical properties

\section{Introduction}

The use of vegetal fibers as reinforcing agent in polymeric composites for automobile and civil industries is getting a new impulse nowadays, though the manufacturing techniques are yet incipient and poorly productive. Mercedes-Benz ${ }^{\circledR}$ vehicles are currently using upholstering made from vegetal fibers.

Some advantages are attributed to the use of vegetal fibers in many industrial applications as compared to synthetic fibers like glass fibers. The vegetal fiber comes from renewable sources; it is biodegradable, atoxic, shows low cost and improved capacity as sound and thermal insulator. It also can absorb moisture from human transpiration. Also, vegetal fibers have lower density and cause lower abrasion in conventional polymer processing devices. Besides vegetal fibers have the advantage of being recyclable and they decompose without toxic compounds production or can be consumed by biodegradation. Consequently, there is no waste generation at the end of the product life cycle.

Another important aspect to be considered in the use of vegetal fibers is the generation of rural and industrial jobs, as reported by Marroquim ${ }^{1}$. Thus, social and environmental implications of their use should also be recognized.

Vegetal fibers like jute, sisal, ramie, coconut and pineapple have been used as reinforcing agent in polymeric matrices ${ }^{2,3}$. Sisal fibers have better performance for commercial applications due to their higher elastic modulus, increased impact strength and moderate tensile and flexion strengths, when compared to other vegetal fibers ${ }^{4,5}$. Oksman et al. ${ }^{6}$ have shown that the incorporation of sisal fiber in an epoxy resin matrix produces a composite material that can be employed in resistant and rigid products.

According to Morassi ${ }^{7}$, sisal fiber, considered as an alternative to glass fiber, can be satisfactorily used as a reinforcing agent in plastic products for many applications in the automobile industry. They include internal lining to cabin sides and ceiling, head support and seat back, external sun protection accessories (sun strips), instrument board, tool bags, cabin/motor encapsulation and bumper. Also, plastic materials reinforced with sisal fibers have been used as substitute for wood plates and in mortar formulation.

The present work describes a process developed for the composite manufacture using conventional techniques for polymers processing. The composite studied was composed by block copolymer styrenebutadiene-styrene (SBS), a thermoplastic polymer used in the shoe industry, and sisal fibers. This work also evaluated the composite hardness, tensile and tear strength as well as the composite morphology. SBS was selected as composite's matrix due to its larger output, the lower cost and more extensive application. SBS can stay in contact with water, weak acids and alkalis and has excellent tensile strength, high surface friction coefficient, good low-temperature behavior, excellent electric properties and great workability. For these reasons, it has become the thermoplastic elastomer with the greatest consumption. In rubber products, SBS is mainly used in shoemaking (shoe soles), rubber hoses and rubber belts.

\section{Materials and Methods}

The composite was manufactured using sisal fibers from Brascorda S. A. (Brazil) and SBS (styrene-butadiene-styrene block copolymer) Coperflex TR from Petroflex S.A.

SBS was used without further purification. Sisal fibers were washed thoroughly in a $0.1 \mathrm{M} \mathrm{NaOH}$ solution, followed by water washing, air drying and cutting in long fiber form of $10 \mathrm{~mm}$ length and short fiber form of $5 \mathrm{~mm}$ of length. The fiber cleaning is an important step for the improvement of fiber processing with polymers. Non-washed sisal fibers had a large amount of impurities. The impurity particles hold to the fibers during extraction and beneficiation steps. Washed fibers were added to an open mixer with mixing rolls (Mecanoplast) in concentrations of 5\%, 10\% and 20\% by weight with respect to pure SBS using an average temperature of $150{ }^{\circ} \mathrm{C}$. The composite blankets were then pressed in a plate form for $30 \mathrm{~s}$ using $75 \mathrm{lbf} / \mathrm{in}^{2}$. Alternatively, SBS/ sisal fiber composites were processed in a Haake single-screw extruder (19 $\mathrm{mm}$ of screw diameter, $\mathrm{L} / \mathrm{D}=25$ ) or in an ICMA double-screw extruder (co-rotating 
screws with $25 \mathrm{~mm}$ of diameter, $\mathrm{L} / \mathrm{D}=44,300 \mathrm{rpm}$ with hammer type mixing elements). The temperature profile varied from $44{ }^{\circ} \mathrm{C}$ (at the loading) to $125^{\circ} \mathrm{C}$ (the maximum) distributed in 14 zones of the double-screw extruder. In all mixtures, $15 \%$ by weight of mineral oil was used as plasticizer.

In order to improve the adhesion at the interface between the vegetal fiber (hydrophilic) and the polymer matrix (hydrophobic), 2 wt. (\%) maleic anhydride (Chemmax) was added as coupling agent in experiments carried out with double-screw extruder.

Composite hardness (shore A scale) was determined using a Bareiss durometer and the tensile strength was evaluated in an EMIC (DL model) universal testing machine, according to ASTM D 142 standard (test specimen - length: $115 \mathrm{~mm}$, width: $25 \mathrm{~mm}$, central width: $6 \mathrm{~mm}$, thickness: $2 \pm 0.2 \mathrm{~mm}$, speed: $500 \mathrm{~mm} / \mathrm{min}$ ). Tear strength tests were performed using an EMIC (DL 2000 model) machine following ASTM D 624 - type C standard. The morphology of the sisal fibers and their distribution in the composite surface were investigated using a PHILIPS XL 20 scanning electron microscope.

Thermogravimetric analysis (TGA) was performed in a TA Instrument TG2050 TGA type in order to investigate the degradation behavior of sisal fiber, SBS and SBS/sisal fiber composite. Samples in the range of $10-15 \mathrm{mg}$ were heated from 20 to $700{ }^{\circ} \mathrm{C}$ at a scanning rate of $20{ }^{\circ} \mathrm{C} / \mathrm{min}$ under nitrogen gas purging.

\section{Results and Discussion}

\subsection{Hardness, tensile and tear strength}

Table 1 shows the results for SBS/sisal composite hardness, besides the hardness of pure SBS, all processed in an open mixer roll. The composite hardness increased with the increased sisal fiber content in the composite. Thus, the sisal fiber is acting as a stiffener for SBS matrix.

Table 2 shows the average results of tensile strength for SBS/ long sisal fiber composites processed in an open mixer roll. SBS/sisal fibers composites showed a decrease in ultimate tensile strength with the sisal fiber content increase probably due to failure points generated by the lack of interfacial adhesion between sisal fiber and the polymer matrix. Also, the elongation at break decreased. However, Young's modulus increased.

Table 3 shows the mechanical properties for SBS/sisal fiber composites and pure SBS processed in a single-screw extruder while Table 4 shows these properties for the same composites and pure SBS processed in a double screw extruder.

According to the average ultimate tensile strength values and average elongation at break values showed in Table 3, fibers addition yield a decrease in ultimate tensile strength with respect to pure SBS and this behavior is independent of the fiber length employed ( 5 or $10 \mathrm{~mm}$ ). Nevertheless, this property had a slight improvement when the composite was processed in a double-screw extruder, according to Table 4. Mattoso, Ferreira and Curvelo ${ }^{9}$ have already observed that the composite processing technique has significant influence in its quality.

Thus, the use of a double-screw extruder for composite manufacture enhanced its mechanical performance since tensile strength and Young's modulus values increased with respect to composites manufactured by other techniques.

Although the double-screw extrusion is a technique that promotes better mixing and homogenization of the materials due to the presence of mixing elements in the screw, the addition of the coupling agent was fundamental in the experiments carried out in a double-screw extruder. As can be observed in Table 4, the addition of maleic anhydride has

Table 1. Hardness of the SBS/long sisal fiber composite and pure SBS.

\begin{tabular}{lc}
\hline Composites & Hardness (shore A) \\
\hline SBS / Sisal 5\% & 57 \\
SBS / Sisal 10\% & 63 \\
SBS / Sisal 20\% & 65 \\
Pure SBS & 47 \\
\hline
\end{tabular}

Table 2. Ultimate tensile strength, Elongation at break and Young's modulus at 10\% of SBS/sisal and pure SBS processed in open mixer rolls.

\begin{tabular}{lcccc}
\hline \multicolumn{1}{c}{ Mechanical properties } & $\begin{array}{c}\text { SBS/Sisal 5\% } \\
(10 \mathrm{~mm})\end{array}$ & $\begin{array}{c}\text { SBS/Sisal 10\% } \\
(10 \mathrm{~mm})\end{array}$ & $\begin{array}{c}\text { SBS/Sisal 20\% } \\
(10 \mathrm{~mm})\end{array}$ & Pure SBS \\
\hline Ultimate tensile strength, MPa & 3.5 & 3.2 & 2.8 & 5.4 \\
Elongation at break, \% & 600 & 600 & 500 & 850 \\
Young's modulus at 10\%, MPa & 0.8 & 0.8 & 1.0 & 0.5 \\
\hline
\end{tabular}

Table 3. Ultimate tensile Strength, Elongation at break and Young's modulus at $10 \%$ of SBS/sisal and pure SBS processed in a single screw extruder.

\begin{tabular}{|c|c|c|c|}
\hline Mechanical properties & $\begin{array}{c}\text { SBS/Sisal 5\% } \\
(10 \mathrm{~mm})\end{array}$ & $\begin{array}{c}\text { SBS/Sisal } 5 \% \\
(5 \mathrm{~mm})\end{array}$ & Pure SBS \\
\hline Ultimate tensile strength, $\mathrm{MPa}$ & 1.74 & 2.63 & 4.9 \\
\hline Elongation at break, $\%$ & 291 & 400 & 700 \\
\hline Young's modulus at $10 \%, \mathrm{MPa}$ & 1.0 & 1.1 & 0.8 \\
\hline
\end{tabular}

Table 4. Ultimate tensile strength, Elongation at break and Young's modulus at 10\% of SBS/sisal and pure SBS processed in a double-screw extruder.

\begin{tabular}{cccc} 
Table 4. Ultimate tensile strength, Elongation at break and Young's modulus at 10\% of SBS/sisal and pure SBS processed in a double-screw extruder. & Pure SBS \\
\hline Mechanical properties & $\begin{array}{c}\text { SBS/Sisal 5\% } \\
(5 \mathrm{~mm} \text { with maleic } \\
\text { anhydride })\end{array}$ & $\begin{array}{c}\text { SBS/Sisal 10\% } \\
\text { (5 m without maleic } \\
\text { anhydride) }\end{array}$ & 4.8 \\
\hline Ultimate tensile strength, MPa & 4.5 & 3 & 705 \\
Elongation at break, $\%$ & 630 & 670 & 1.2 \\
Young's modulus at 10\%, MPa & 1.5 & 1.0 & 405 \\
\hline
\end{tabular}


markedly increased the ultimate tensile strength values and Young's modulus. It however reduced the elongation at break values. Some authors have already reported the enhancement of the mechanical properties of the polymeric composites due to the addition of the coupling agent. Arzondo et al. ${ }^{10}$ showed that the fiber breakage is reduced to a minimum, even for recycled composites, in the presence of a coupling agent. Also, Mohanty et al. ${ }^{11}$ reported that the addition of coupling agents to the fibers resulted in an improvement of the stiffness of the treated composites.

Analyzing the values of Young's modulus at 10\%, the fibers addition in SBS matrix has increased the modulus for all types of processing techniques. The highest modulus were obtained for composites composed by short sisal fibers ( $5 \mathrm{~mm}$ of length) with the addition of $2 \%$ by weight of maleic anhydride and processed in a double-screw extruder. Arzondo et al. ${ }^{12}$ suggested that the sisal fiber content in the composites with polypropylene (PP) using maleic anhydride as coupling agent causes three simultaneous effects, which clearly show that the fibers are strongly bonded to the PP matrix: a) the composite tensile modulus increases, b) the tensile strength increases and c) the elongation at break is reduced.

This work also showed that the maleic anhydride has optimized the SBS/fiber composite mechanical performance probably avoiding failure points caused by the poor adhesion at SBS/fiber interface. Thus, sisal fibers that are well bonded to the SBS matrix stiffen the composite which looses its elastomeric behavior, i.e., increase tensile modulus and Young's modulus. The sisal fibers also decrease elongation at break.

The mechanism of interaction between the coupling agent, the sisal fiber and the SBS polymer matrix must be better understood in order to find the optimum concentration of both, sisal fiber and coupling agent, in the polymer matrix.

The tear strength is also an important property for material evaluation in the shoe industry. The SBS/short sisal fiber composites processed in a double-screw extruder without maleic anhydride showed an average value of $13 \mathrm{~N} / \mathrm{mm}$ for tear strength, while using maleic anhydride the tear strength increased to an average value of $13.79 \mathrm{~N} / \mathrm{mm}$. The pure SBS showed tear strength of $6 \mathrm{~N} / \mathrm{mm}$ on the average. These experiments showed that the sisal fiber enhances the tear strength of SBS.

\subsection{Thermal analysis}

According to Figure 1a,b and c, the SBS thermal profile was not affected by sisal fiber addition. In Figure 1b, the TGA curves show the degradation steps attributed to the components of the sisal fiber: hemicellulose degradation (at approximately $250{ }^{\circ} \mathrm{C}$ ) and lignin and cellulose degradation with carbon waste generation (at approximately $350{ }^{\circ} \mathrm{C}$ ). Below $100{ }^{\circ} \mathrm{C}$ the mass loss is equivalent to the moisture percentage of the fiber (around 8\%). The SBS degradation started at about $420{ }^{\circ} \mathrm{C}$, as observed by Picchioni et al. ${ }^{13}$. The thermal event that occurred at $300{ }^{\circ} \mathrm{C}$ is attributed to paraffinic oil degradation.

\subsection{Composite morphological analysis}

Even through a visual inspection it is possible to find sisal fibers in composite surface as well as inside of it, independently of the fiber content in the composite and technique of processing. On the other hand, the sisal fiber showed a random distribution in SBS matrix, without a preferential orientation (Figures 2 e 3). According to Joseph, Medeiros and Carvalho ${ }^{14}$ that worked with hybrid tissues composed by sisal fiber, glass fiber and a polyester matrix produced by compression molding, the composites with unidirectional fibers showed higher mechanical performance than composites with random fibers when tests were performed longitudinally to the reinforcing

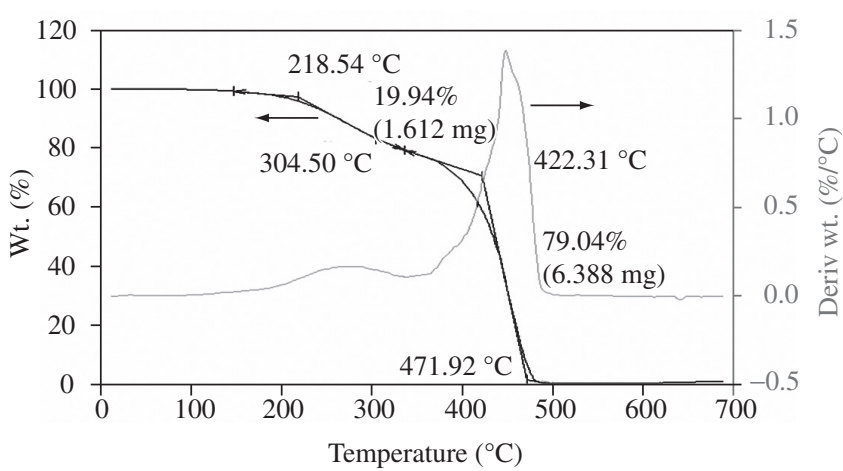

(a)

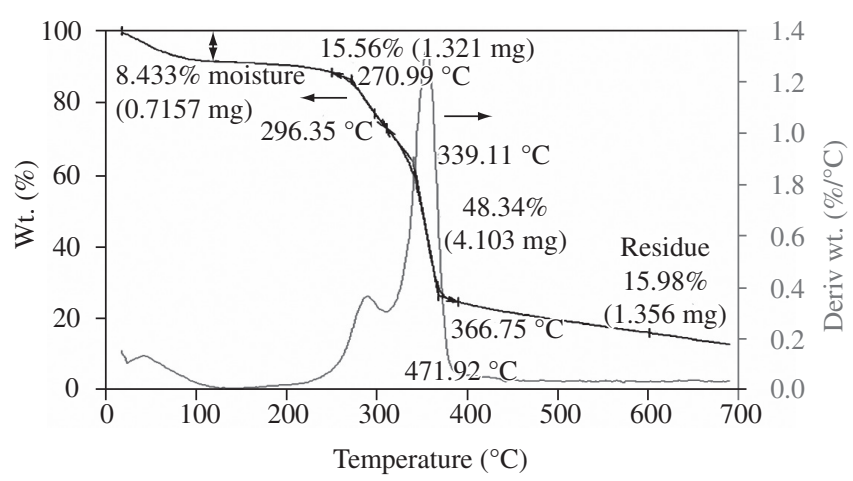

(b)

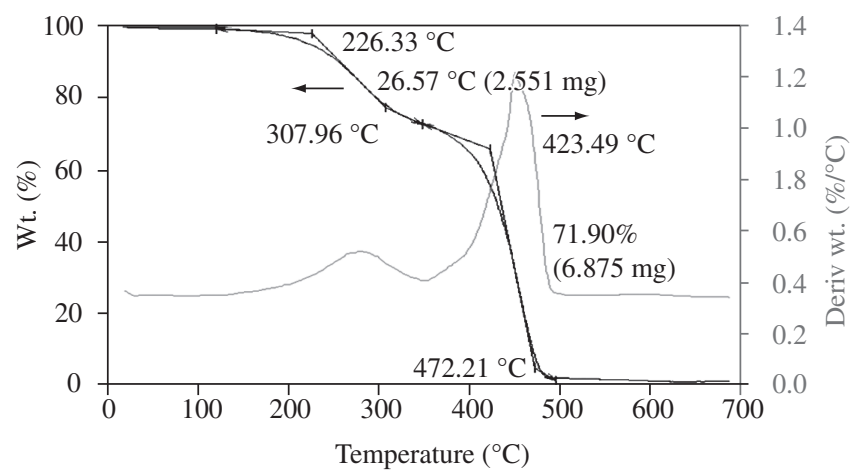

Figure 1. TGA curve for: a) SBS matrix, b) sisal fiber and c) SBS/10\% sisal fiber composite (long fiber).

agent. There is no possibility for fiber orientation employing the processing techniques used in this work due to the small length of the sisal fibers and to the strong mixing promoted by the two screws. However, polymer composites with sisal fiber are easily processed at low cost in a double screw extruder. Figures 2 and 3 show the better homogenization and distribution of the sisal fibers in the composite manufactured using the double-screw extruder. Figure 4 shows the surface morphology of a cross-section sample of SBS/sisal fiber composite processed in a double-screw extruder using maleic anhydride as coupling agent. Figure 4 is similar to Figure 3a, however there are less little holes that could indicate the better adherence of the sisal fiber to the polymeric matrix. Thus, the mechanism of failure in the case of composites without maleic anhydride, where the adhesion is poor, probably occurs by fiber pullout and is indicated by holes and fiber ends and in the case of composites with maleic anhydride occurs by fiber breakage. 


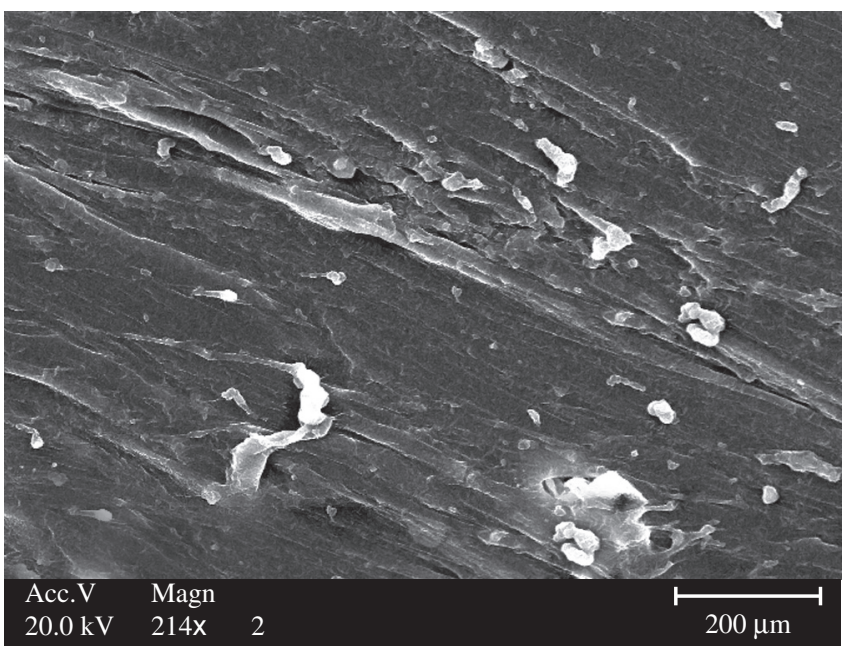

(a)

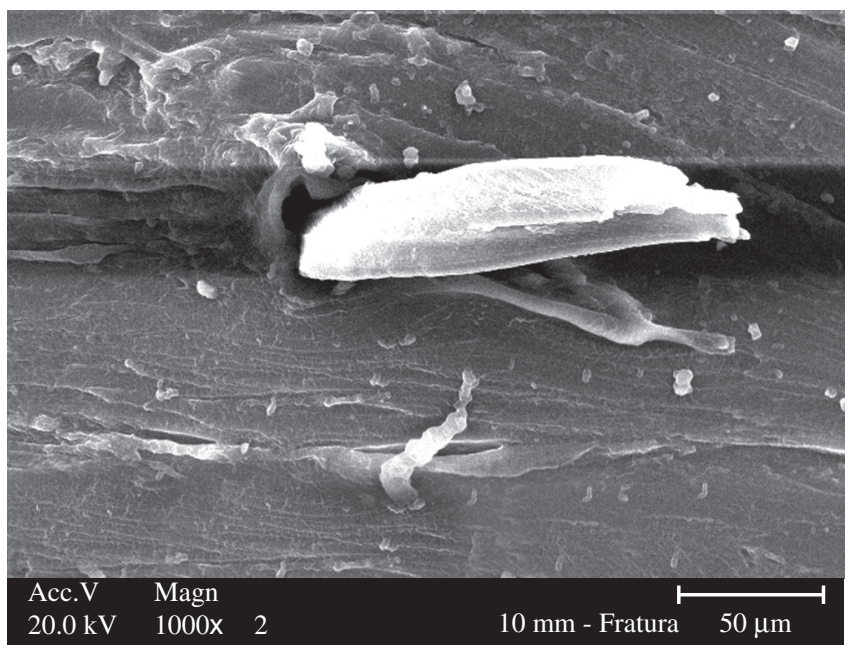

(b)

Figure 2. Scanning electronic micrographs of SBS/5\% short sisal fiber composites processed in a single-screw extruder: a) short magnification and b) higher magnification - fiber detail.

\section{Conclusion}

SBS/short sisal fiber composite processed in a double-screw extruder using $2 \%$ by weight of maleic anhydride and $5 \%$ by weight of fiber content showed the best mechanical performance among the composites manufactured in this work. Properties like tensile strength and elongation at break showed a slight reduction with respect to pure SBS, however Young's modulus increased remarkably, indicating that the composite is becoming more rigid. The tear strength of the composite increased more than twice in relation to pure SBS. Thus, the SBS/short sisal fiber composite has a great potential for use in the shoe industry as shoe soles and sandal strips. The concentration of the maleic anhydride coupling agent in the composite must be optimized in order to increase the tensile strength in such a way that SBS/short sisal fiber composites can be used in applications that require improved mechanical properties. Thus, the use of sisal fiber in polymeric composites could contribute to sustainable development in a close future.

\section{Acknowledgements}

The authors are grateful to Universidade Luterana do Brasil (ULBRA) and Fundação de Amparo à Pesquisa do Rio Grande do

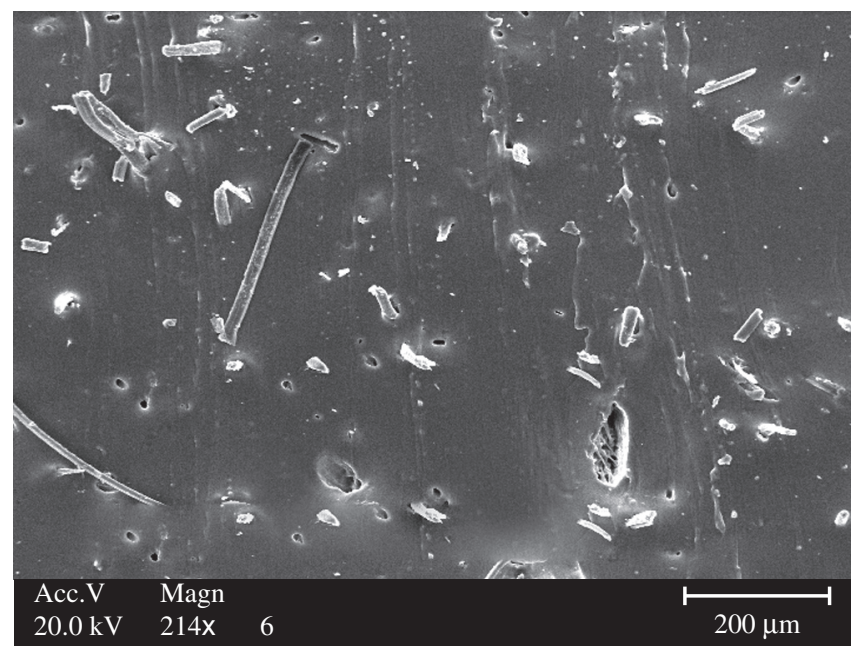

(a)

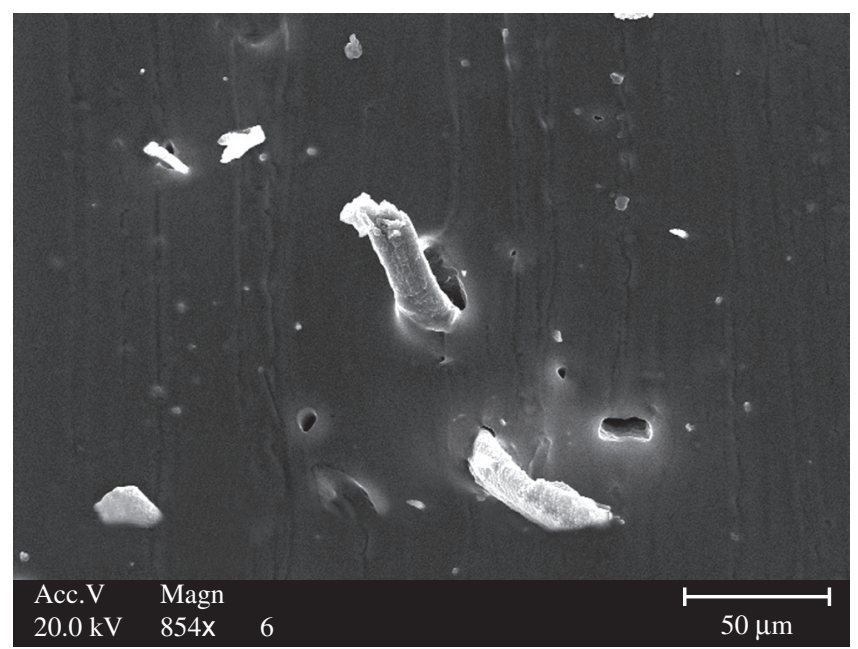

(b)

Figure 3. Scanning electronic micrographs of SBS/5\% short sisal fiber composites processed in a double-screw extruder: a) short magnification and b) higher magnification - fiber detail.

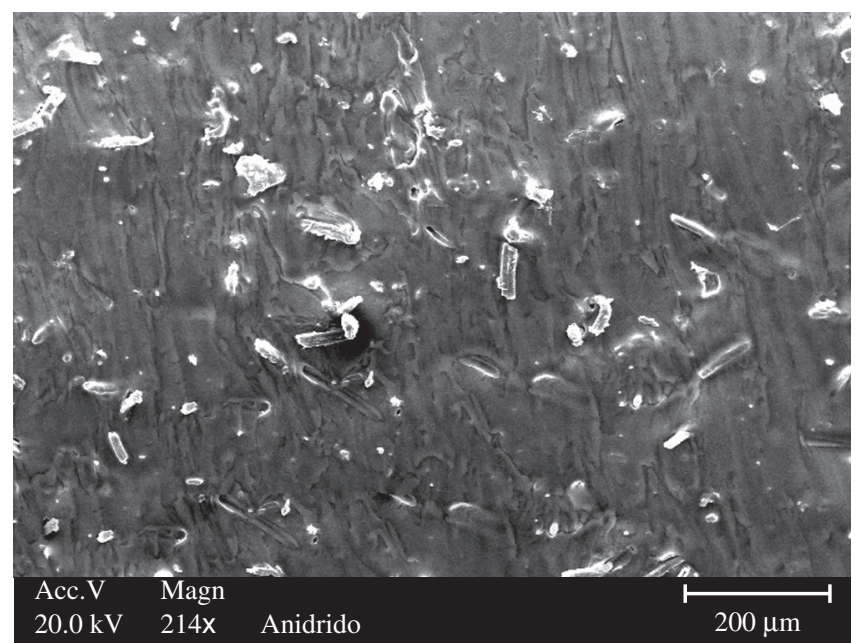

Figure 4. Scanning electronic micrographs of SBS/5\% short sisal fiber composites processed in a double-screw extruder with maleic anhydride as coupling agent. 
Sul (FAPERGS) for financial support. The authors also thank the Centro de Microscopia Eletrônica e Microanálise (ULBRA) for SEM micrographs.

\section{References}

1. Marroquim S. Uso da fibra de coco e látex na engenharia automotiva: memorial da Crina-Látex do Brasil. Associação Brasileira da Agroindústria do Coco (ABRACOCO); 1994.

2. McLaughlin EC. The strength of bagasse fiber-reinforced composites. Journal of Materials Science. 1980; 15(4):886-890.

3. Prasad SV, Pavithran C, Rohatgi PK. Alkali treatment of coir fibers for coir-polyester composites. Journal of Materials Science 1983; 18(5):1443-1454.

4. Pavithran C, Mukherjee PS, Brahmakumar M, Damodaran AD. Impact properties of natural fiber composites. Journal of Materials Science Letters 1987; 6(8):882-884.

5. Pavithran C, Mukherjee PS, Brahmakumar M, Damodaran AD. Impact performance of sisal-polyester composites. Journal of Materials Science Letters 1988; 7(8):825-826.

6. Oksman K, Wallström L, Berglund LA, Toledo Filho RD. Morphology and mechanical properties of unidirectional sisal-epoxy composites. Journal of Applied Polymer Science 2002; 84(13):2358-2365.

7. Morassi JO. Fibras naturais: aspectos gerais e aplicação na indústria automobilística. Mercedes Benz of Brazil; 1994.
8. Andrade Jr. TE, Martinelli AE, Melo DMA, Nascimento RM, Rambo C, Sieber H, Greil P. Infiltração de Sal de Alumínio em Fibras de Sisal para Obtenção de Fibras de Alumínio. Cerâmica. 2005; 51(317):37-41.

9. Mattoso LHC, Ferreira FC, Curvelo AAS. Sisal fiber: morphology and applications in polymer composites. In: Proceedings of the International Symposium on Lignocellulosic-Plastics Composites; 1996; São PauloSP.

10. Arzondo LM, Pérez CJ, Carela JM. Injection molding of long sisalreinforced polypropylene: Effect of compatibilizer concentration and viscosity of fiber adhesion and thermal degradation. Polymer Engineering and Science 2005; 45(44):613-621.

11. Mohanthy S, Verna SK, Nayak SK, Tripathy SS. Influence of fiber treatment on the performance of sisal-polypropylene composites. Journal of Applied Polymer Science 2004; 94(3):1336-1345.

12. Arzondo LM, Vazquez A, Carella JM, Pastor JM. A low-cost, low-fiber-breakage, injection molding process for long sisal fiber reinforced polypropylene. Polymer Engineering and Science. 2004; 44 (9):766-1772.

13. Picchioni F, Casentini E, Passaglia E, Ruggeri G. Blends of SBS triblock copolymer with poly(2,6-dimethyl-1,4-phenylene oxide)/polystyrene mixture. Journal of Applied Polymer Science. 2003; 88(11):2698-2705.

14. Joseph K, Medeiros ES, Carvalho LH. Tensile properties of unsaturated polyester composites reinforced by short sisal fibers. Polímeros 1999; 9(4):136-141. 